\title{
The Approach of Enhancing Regional Modern Manufacturing and R\&D Transformation Function -a Case of Tianjin Binhai New Area, China
}

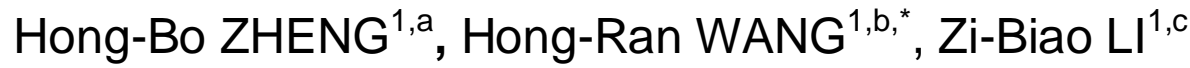 \\ ${ }^{1}$ School of Economics and Management, Hebei University of Technology, Tianjin, China \\ a1127395236@qq.com, b874634989@qq.com, c30049160@qq.com \\ ${ }^{*}$ Corresponding author
}

Keywords: independent brand, industrial chain, modern manufacturing, R\&D transformation.

\begin{abstract}
R\&D transformation function is an important symbol of regional innovation capability, the development level of manufacturing industry is an important manifestation of regional competitiveness. Taking Binhai New Area as an example, through studying the modern manufacturing and R\&D transformation function in Tianjin Binhai New Area, this paper analyzes the development level of manufacturing industry and $R \& D$ transformation function on the regional aspect, proposes focal points of work and supporting measures to promote Binhai New Area into a high level of modern manufacturing and R\&D transformation base.
\end{abstract}

\section{Introduction}

Tianjin Binhai New Area is an important growth pole of regional economics in China. "Strive to build a high level of modern manufacturing and R\&D transformation base" is an important part of the functional orientation of Binhai New Area which is bestowed by the State Council[1]. To achieve this functional orientation and enhance the ability of radiation to drive the regional economy, it is necessary to further promote innovation capacity, service capability and international competitiveness. Therefore, to enhance modern manufacturing and $\mathrm{R} \& \mathrm{D}$ transformation function in Binhai New Area is of great significance.

\section{The current situation of modern manufacturing and R\&D transformation in Binhai New Area}

Years of development and construction have witnessed the rapid development of modern manufacturing and great improvement in technological innovation capability in Binhai New Area[2].

R\&D transformation platform has been gradually perfected and the innovation ability has significantly improved

Binhai New Area accelerates the construction of major platform for innovation, which makes the technological infrastructure further improved and the ability to aggregate domestic and foreign resources for innovation significantly enhanced. Currently, the Binhai New Area has completed a total of 50 national and provincial R\&D centers, 22 key laboratories above the municipal level, 10 industrial technology innovation alliances, 9 enterprise technology innovation platforms, 40 incubators, 10 industrial technology R\&D centers, among which 5 enterprise technology R\&D centers have risen to national level[3]. In 2011, the patent applications in Binhai New Area reached to 11,855 , of which 5649 were granted, and the amount effective patent were 11553. Binhai New Area actively supports the growth of high-tech SME, as of the end of 2011, 653 were identified as the national high-tech enterprises, accounting for $72 \%$ of the entire Tianjin.

The industrial scale has been continually expanded and the structure has been gradually optimized

The important requirement for national construction of high-tech industrial development and 
transformation base has been achieved. Taking the aerospace, petrochemical, automobile and equipment manufacturing, electronic information, biological medicine, new energy and new material industries as a breakthrough, the total industrial output value of these dominant industries has reached to 1.15308 trillion, accounting for $90.6 \%$ of industrial output value in the entire region, and the industrial output value of high-tech industry accounting for $43 \%$ of the Binhai New Area's industrial output value[4]. A modern industrial system which takes the strategic emerging industry as the forerunner, the high-tech industry as the leader and the dominant pillar industry as the mainstay has been built up in Binhai New Area.

\section{The industrial agglomeration effect has been appeared and the transformation of development pattern has been accelerated}

Binhai New Area focuses on the development of industrial clusters. It has formed a good momentum of function complementary among Development Park and the relative concentration of industry. All of these lay the foundation for the intensive development of Binhai New Area's industry[5]. Binhai New Area also actively explore recycling economy development model. Tianjin Economic and Technological Development Zone, Port Economic Zone and Northern Power Plant are all included in the national circular economy demonstration areas. The development mode of manufacturing industry in Binhai New Area have gradually transformed to high-end, high-quality, high-tech level. And the quality and efficiency of economic development has improved step by step.

\section{The drawbacks of Binhai New Area in the aspects of R\&D and manufacturing function}

The development of manufacturing industry in Binhai New Area has made remarkable achievements, but there is still large room to improve and strengthen to meet the national expectation: firstly, there are many general multiprocessing industries, R\&D design and creativity need to be improved, the brand needs to be cultivated; secondly, industrial development is not coordinated, industrial layout also should be further concentrated, cluster development and the chain improvement need to be further strengthened; thirdly, its own R\&D strength and independent innovation capability is not strong enough, the dependence on external resources and technology is excessive, and the independent research and development need to be improved; finally, the supporting role that technological R\&D played in the development and opening of Binhai New Area is insufficient, the powerful leading innovation industries need to be developed.

\section{The key work to improve modern manufacturing and R\&D transformation function in Binhai New Area}

To further enhance the modern manufacturing and R\&D transformation function, Binhai New Area should actively build R\&D transformation platform, improve the industrial chain system, cultivate independent brand, and unceasingly promote the industry to a high level[6].

\section{To build four top platforms to enhance the R\&D transformation function}

1. R\&D transformation platform. Pointing to the crucial development of the industrial chain, a number of functional public R\&D transformation institutions should be constructed, the service resources of university research collaboration should be integrated, chances of public innovation and entrepreneurship and common technical service should be provided[7]. Binhai New Area should strongly rely on the International Joint Research of Biomedicine, build a large biomedical R\&D transformation platform of high level; rely on National Super Computer Center in Tianjin, build a large national super computer R\&D transformation platform; rely on the Binhai New Area in Tianjin, establish new energy development institute for the whole country and build new energy technology R\&D transformation platform.

2. Incubation platform. Binhai New Area should enhance the construction of professional incubator, make the Wahson biological park, TEDA Nano industrial base, marine high-tech industrial park, software industrial park, airport science city, the national civil aviation hi-tech 
industrial transformation base and other technical enterprise incubation base become bigger and stronger. The "three-level incubation" system should be improved, comprehensive accelerators should be built up and the development space of business incubators should be guaranteed to enable the enterprises to achieve a rapid growth.

3. Sharing platform. According to the construction of science and technology service system, Binhai New Area should focus on the technology of information service platform specifying to the work from business, industry and government[8]. The food safety technical inspection, drug safety evaluation and a batch of new testing agencies of national level should be constructed to achieve the metering and testing functions of national and municipal level and make the Traditional Chinese Medicine Research and Testing Center, high-performance battery testing center and other professional testing institutions reach to their full potential. Ensure the Tech-SME can gain full strength to innovate and start business with the advantages of higher education institutions, scientific research institutions, and industrial common technology service platforms such as IC design service centers, software evaluation centers and supercomputing centers.

4. Service Platform. The region needs to enhance the specialized service level such as strategic consulting, productivity, technology transfer, science and technology policy, and result transformation. In order to promote the ability of the public technology services, national and municipal technology service organizations are encouraged to set up branches [9]. The science and technology intermediary services of government purchase and decision-making advisory procurement system should be set up. The quality certification system should be built up to attract the well-known overseas engineering designs, technical consultations, inspection laboratories and other intermediary service institutions to enter into Binhai New Area.

\section{To tensile the chain of strategic emerging industry and enhance the radiation ability of modern manufacturing}

1. Petrochemical industrial chain. Leading by the large ethylene and oil refining and other major projects, accelerating the extension of industrial chain, focusing on the industrial chain of bulk products such as organic materials, general synthetic resins, general synthetic rubbers, synthetic fiber materials, extending to build up rubber processing and textile industries in downstream, the ultimate target of this project is to build up a complete industrial chain of "oil-chemical-textile" , which takes the oil as the head and textile as the tail.

2. Automotive industrial chain. In this aspect, focusing on the vehicle manufacturing like FAW Toyota, Great Wall Motor, with active introduction and improvement of the spare parts industry, extending the chain of the upstream and downstream automotive industry, and the final aim of this project is to build up a complete chain of entire vehicle manufacturing and spare parts industry[10].

3. Industrial chain of Internet cloud computing. Taking Samsung, National Supercomputer Center, Samsung Mobile Display and other leading enterprises as the basis, strengthening the midstream industrial chain with cloud computing, mobile Internet, new display industry, and enhancing the development and design of the Internet comprehensive system as well as their applications in the manufacturing and service industry, the ultimate goal of this project is to cultivate and perfect the Internet industrial chain.

4. Aerospace industrial chain. Taking the Airbus A320 final assembly project as the basis, with the introduction of both prime suppliers providing the large parts of the Airbus aircraft and second suppliers providing spare parts, extending to the upstream of $R \& D$ and downstream of aviation maintenance, aircraft leasing, aviation exhibition and aeronautical information service, taking the large rockets, satellites, space stations and other spacecraft systems integration as the core, the project focuses on the development of key components of spacecraft and device in upstream industry and the satellite application and space extension in downstream industry[11].

5. Green energy industrial chain. As for this aspect, paying more attention to improving the downstream industrial chain of wind power, crystalline silicon cells, LED, lithium-ion batteries industry, strengthening R\&D of the core technologies, perfecting the industrial development of 
ancillary services, expanding the application scale of enterprise products, and the final goal of this project is to make the upstream and midstream industrial chain bigger and stronger.

\section{To cultivate independent brands and promote the embeddings of modern manufacturing}

In this aspect, the implementation of brand strategy and technology standardization strategy shall be actively promoted. The formulation of incentive policies for enterprises creating new famous brands should be accelerated, the marketing publicity of famous-brand products should be strengthened, the identification and evaluation criteria of branded products should be standardized and improved, and then a favorable policy environment for brands development should be built up[12]. We will provide more supports to the products which meet the brand standards, and actively cultivate potential products and advance their growth as quickly as possible. We will endeavor to cultivate a batch of Tianjin brands even Chinese brands as soon as possible, and construct a group of independent brands which will be competitive in China even in the world.

\section{Security measures to improve modern manufacturing and $R \& D$ transformation function in Binhai New Area}

\section{To perfect the plan and take the project construction as the focal point}

More instructions, managing and coordinating skills should be given to major projects which are crucial to the improvement and conversion of the modern manufacturing[13]. In accordance with the national industrial policies, we should assist enterprises to outline sound development planning, seriously grasp market positioning, select projects with high starting point and high quality, make efforts to defuse enterprise investment risks, and improve the success rates of projects.

\section{To increase financial support}

In Binhai New Area, the financial institutions should be encouraged to participate in the upgrading projects of modern manufacturing, broaden the financing channels and support enterprises to raise funds through issuing shares and corporate bonds, financing projects, restructuring assets and replacing share equity etc. What's more, the performance appraisal and evaluation to the special funds in financial industries should be strengthened, the guiding and promoting functions of special funds should be fully achieved, the mechanism of steady growth in financial investment should be perfected, the instructing function of the financial resources for technological innovation activities should be fully exerted, the major technical researches and the scientific and technological transformation achievements should be given focal support.

\section{To perfect the implementation of various policies}

Increasing the collaborative efforts of existing policies, optimizing innovation policy systems with its own characteristics, perfecting factor market construction and personnel cited mechanism, intensifying efforts to preach and implement the related industrial and innovation policies in Binhai New Area, in Tianjin and in China, the ultimate aim of this project is to enable enterprises to truly receive various preferential taxation[14].

\section{To improve the industrial development environment}

Binhai New Area ought to reform the government service forms. It is necessary to promote the transformation of government functions, improve service initiatives and advance the public service innovation. It is imperative to deepen the reform of administrative approval systems, simplify administrative links, optimize work processes and enhance work efficiency[15]. The sharing mechanism of administrative information resources should be built up and the information sharing scope should be expanded. 


\section{References}

[1] Zhang Qiuying, Study on transformation of R\&D under reform and openness and self-innovation in Tianjin Binhai New Area: the view point of development of embedded character of RJVs, Chinese Journal of Management Science, vol.18, no.6, 2010, pp.171-176.

[2] Ren Xiukui, Zhu Shiming, The research of establishing R\&D transformation base in Tianjin Binhai New Area, Port Economy, no.10, 2008, pp.33-35.

[3] Zang Xueying, Strategic thinking of building high level of modern manufacturing and R\&D transformation base in Binhai New Area, Port Economy, no.7, 2007, pp.16-19.

[4] Ma Huzhao, He Jing, The study on development model transformation of information industry R\&D transformation base in Binhai New Area, China Science and Technology Forum, no.4, 2009, pp.92-96.

[5] Zhao Hong, Ma Tao, An analysis on setting up a center of R\&D and transformation in Tianjin New Coastal District, Science of Science and Management of S. \& T., no.9, 2008, pp.41-47.

[6] Bartlett, C.A., Ghoshal, S, Transnational Management ( Second Edition), Chicago,IL:Irwin (1995).

[7] $\mathrm{Wu}$ Jianxin, On location and related development of advanced manufacturing industry in national region plans, Economy and Management, vol.25, no.4, 2011, pp.41-44.

[8] Gann M, Salter J, Innovation in project-based, service-enhanced firms: the construction of complex products and systems, Research Policy, no.29, 2002, pp.955-972.

[9] Pappas N, Sheehan P, The new manufacturing: linkages between production and services activities, working for the future: technology and employment in the Global Knowledge Economy, Melbourne: Victoria University Press (1998).

[10] Drucker P F, The emerging theory of manufacturing, Harvard Business Review, vol.68, no.3, 1990, pp.94-102.

[11] Szalavetz A, Tertiarization of manufacturing industry in the New Economy: experiences in Hungarian Companies, Budapest: Hungarian Academy of Sciences Working Papers (2003).

[12] Lang Yifu, Zhou Rong, Yu Dengke, Promoting routes and policy analysis of innovation ability of independent brands based on mutual-action between enterprises and government, Science \& Technology Progress and Policy, vol.27, no.9, 2010, pp:85-88.

[13] Kelley, Brand synthesis: the multidimensionality of Brand Knowledge, Journal of Consumer Research, vol.54, no.6, 2003, pp.195-213.

[14] Yu Junli, Study on the model and implementation strategy of research and technology transfer in China hi-tech zone, Science \& Technology Progress and Policy, vol.30, no.1, 2013, pp.63-68.

[15] Reus,T. H., Ritchie, W. J., Ii, Parent and environmental factors influencing the operation of international joint ventures: 15 years of research, Management International Review, vol.44, 2004, pp.369 -395. 